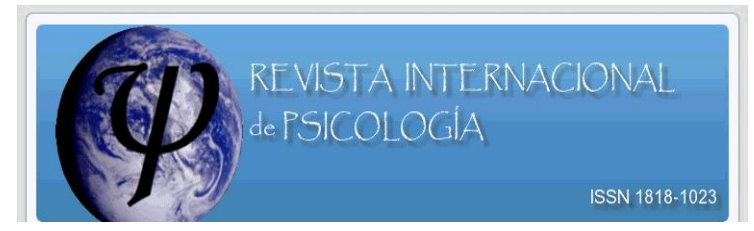

\title{
El vínculo fraterno y su implicancia en la estructuración psíquica
}

\section{Lic. Daniel A. Fernández ${ }^{1}$}

En la clínica psicoanalítica, frecuentemente, se hace gran hincapié en los vínculos parentales. Sin embargo muchas veces se comete el grave error de descuidar otro tipo de vínculo igual de trascendente: el vínculo fraterno. Y es debido a la profunda relevancia de dicho vínculo que resultaría conveniente, al menos en parte, hacer ciertas menciones al respecto.

En principio, podemos recordar que ya desde los tiempos primordiales de la Biblia, los padecimientos de José (hijo predilecto de Jacob) por causa de sus hermanos nos dan muestra de un exceso de celos fraternos y de sus severas consecuencias. Y justamente Freud (1939/1997) hacía referencia a la saga de José, poniéndola de ejemplo para hacernos notar hasta qué punto podían conducir los celos entre hermanos. También el mito de Caín y Abel es otro ejemplo bíblico de un vínculo fraterno trágico. Y sobre este mito, Aguinis M. (1988 citado en Kancyper, 2004) reflexiona que ha sido objeto de estudios a lo largo de innumerables generaciones no sólo por sus enseñanzas o por la turbación que produce, sino también por los enigmas que encierra. Podríamos pensar que, tanto el caso de José y sus hermanos como el ejemplo de Caín y Abel, son muestras claras de lo que afirma Kancyper L. (2004) al decir que los resentimientos que surgen a partir de la dinámica vincular fraterna suelen tener tal relevancia en algunos sujetos, que hasta pueden determinar, en gran medida, el destino de sus vidas y de sus descendientes.

Por lo hasta aquí expresado, no es difícil entonces suponer la existencia de un complejo fraterno. Recordemos que por complejo se entiende un "conjunto organizado de representaciones y de recuerdos dotados de intenso valor afectivo, parcial o totalmente inconscientes" (Laplanche J. \& Pontalis J., 1993, p. 55). Y Kancyper (2004) se ocupará del estudio del complejo fraterno y lo definirá como un "conjunto organizado de deseos hostiles y amorosos que el niño experimenta respecto de sus hermanos" (p. 243). Este complejo mencionado tiene fundamental importancia sobre la estructuración de la vida psíquica, dado que suele recubrir parcial o totalmente la estructura edípica, generando confusión, superponiendo roles y, como consecuencia,

\footnotetext{
${ }^{1}$ Universidad Argentina John F. Kennedy. Correo electrónico: danielfernandez@ @lashmail.com
} 
perturbando gravemente al proceso de la identidad. No se trata de declarar la caducidad del complejo de Edipo, que constituye el complejo genuino de la neurosis. De lo que se trata, más bien, es de descomprimir este último y articularlo con las especificidades de las estructuras narcisista y fraterna. Entre estas tres estructuras, se trama una combinatoria singular y original que determina en cada sujeto la plasmación de una irrepetible e inacabada identidad. Podríamos decir que el complejo fraterno y el edípico se articulan y refuerzan entre sí. Laplanche (citado en Kancyper, 2004) anuncia que el triángulo de rivalidad fraterna está conformado por el niño/a, los padres y el hermano/a (mientras que el triángulo edípico está formado por el niño/a, el padre y la madre), y refiere a que no debe ser considerado cronológicamente anterior al triángulo sexual del Edipo.

Dando cuentas del complejo fraterno, Kancyper (2004) explica cómo el hijo preferido se convierte en un injusto hermano usurpador, pues monopoliza las mejores condiciones del medio familiar al apoderarse del sector más valioso del proyecto identificatorio parental. Esta situación desencadena sentimientos de rivalidad, celos y envidia (estructura que nos remite nuevamente al relato bíblico de José y sus hermanos). Instala, además, al hermano desposeído en el lugar de un rencoroso ciudadano de segundo grado, al que injustamente le han sido cercenados los derechos y las posibilidades de desarrollo por culpa del hijo elegido. Desde este indigno lugar, el hermano damnificado extrae un autolegalizado derecho a la represalia sobre el hermano beneficiado. Ese lugar le concede un incuestionable sentimiento de superioridad para punir y atormentar. A su vez, el hermano preferido padece de sobresaltos, de remordimientos, como consecuencia de los reproches proferidos por el hermano injuriado (en la realidad material) y por sus propias fantasías furtivas.

La protesta fraterna, que para Kancyper (2004) consiste en una agresión franca y un rechazo indignado por parte de un hermano hacia otro (quien según el primero estaría ocupando injustamente un lugar más favorecido), se puede entender desde la lógica del narcisismo. Es decir que el hermano que se cree damnificado no oculta su hostilidad, sencillamente, porque la presencia del otro es vivida como la de un rival e intruso que atenta contra la legitimidad de sus derechos. Y esta rivalidad entre hermanos tiene tal relevancia, que ya Freud (1920/1997) en Sobre la psicogénesis de un caso de homosexualidad femenina consideró que podía, incluso, influir en la determinación de 
la elección de objeto sexual y en el ámbito de la elección vocacional.

El complejo fraterno al que hace referencia Kancyper (2004) cumple con cuatro funciones íntimamente relacionadas:

- Función sustitutiva: Esta función se presenta como una alternativa para reemplazar y compensar funciones parentales fallidas. Esta función sustitutiva ya la describe Freud (1916/1997) en Desarrollo de la libido y organizaciones sexuales, donde pone de ejemplo al niño que toma a la hermana como objeto de amor en sustitución de la madre, debido a que esta última le sería infiel con el padre. Y también Freud, en ese mismo texto, ejemplifica la función sustitutiva al explicar cómo una niña puede encontrar en el hermano mayor un sustituto del padre (quien ya no se ocupa de ella con la ternura de los primeros años), o cómo puede esa misma niña tomar a un hermanito menor como sustituto del bebé que en vano deseó del padre.

- Función defensiva: Esta función se manifiesta cuando el complejo fraterno encubre situaciones conflictivas edípicas y/o narcisistas no resueltas. En muchos casos, sirve para eludir y desmentir la confrontación generacional, así como para obturar las angustias. Esta función defensiva se ve facilitada por el desplazamiento. Y defiende de las angustias y sentimientos hostiles relacionados con los progenitores, justamente, porque dichas angustias y sentimientos son desplazados sobre los hermanos.

- Función elaborativa: Esta función actúa colaborando en la elaboración del complejo de Edipo y del narcisismo. Así como el complejo de Edipo pone límite a la ilusión de omnipotencia del narcisismo, también el complejo fraterno participa en la tramitación y el desasimiento del poder vertical detentado por las figuras edípicas. El sujeto que permanece fijado a traumas fraternos, no logra una adecuada superación de la conflictiva edípica y permanece en una atormentada rivalidad con sus semejantes. 
- Función estructurante: El complejo fraterno cumple un papel estructurante en la organización de la vida anímica del individuo, de los pueblos y de la cultura. Influye sobre la génesis y el mantenimiento de los procesos identificatorios en el yo y en los grupos, en la constitución del superyó e ideal del yo, y en la elección del objeto de amor.

Cada hermano, desde su diferente lugar en el orden de nacimiento, porta además diversas protestas fraternas. Incluso en la observación cotidiana, se detecta cómo el anuncio del nacimiento de un hermano provoca una súbita herida narcisista acompañada de encarnizadas protestas y rivalidades. Esa posición que ocupará el niño dentro de la serie de nacimientos guarda tal trascendencia, que ya Freud (1916 citado en Kancyper, 2004) señalaba que dicha posición era un factor relevante para la conformación de la vida ulterior y que siempre era preciso tomarla en cuenta en la descripción de una vida. También Adler A. (citado en Coscio y Sánchez, 1999) opinaba que el orden y la relación con los hermanos en la constelación familiar, eran factores que influían en el desarrollo del carácter y generaban conflictos debido a la lucha por el poder dentro de la familia.

Acerca del primogénito, Kancyper (1989) dice que "es el primer heredero que anuncia la muerte a la inmortalidad de su progenitor y sobrelleva una mayor ambivalencia y rivalidad por parte del padre" (p. 35). Este padre, a través del primogénito, procuraría según Kancyper (2004) recuperar el estado llamado de omnipotencia del narcisismo infantil. Investiría así a ese primogénito como su doble especular, ideal e inmortal. Se le adjudicarían a dicho hijo identificaciones preestablecidas, mientras que sobre el segundo hijo recaerían idealizaciones menos directas y masivas e identificaciones menos precisas. Se podría pensar, entonces, que esas diferencias entre el primogénito y los hermanos subsiguientes generarían inevitablemente entre ellos recíprocas rivalidades. Y la rivalidad que suelen manifestar los primogénitos con los hermanos subsiguientes, podría deberse a que consideran a estos últimos intrusos, dobles consanguíneos que intentan destronarlo. Adler (citado en Coscio y Sánchez, 1999) se refiere al primogénito como al "príncipe heredero" que, como tal, estructura rasgos conservadores como forma de asegurarse un lugar frente al peligro de su posible suplantación por los hermanos. 
La clínica psicoanalítica revela que, con gran frecuencia, suele ser el hermano menor el que intenta descubrir, conquistar y cultivar los nuevos territorios; mientras que el hermano mayor suele asumirse como el epígono de la generación precedente, sobrellevando el ambivalente peso de actuar como el continuador y el defensor que sella la inmortalidad de sus predecesores (Kancyper, 2004). El hijo mayor suele ser identificado, desde el proyecto identificatorio parental, como el destinado a ocupar el lugar de la prolongación y fusión con la identidad del padre. Esta identificación es inmediata, directa y especular. El hijo mayor se encuentra programado como aquel que llega al mundo para resanar las heridas narcisistas del padre y para completarlo; el hijo menor, en cambio, para nivelar la homeostasis del sistema materno. La experiencia psicoanalítica nos enseña que la rígida división del "botín de los hijos", ofrendados como meros objetos para regular la estabilidad psíquica de la pareja parental, es punto de severas perturbaciones en la plasmación de la identidad sexual y en el despliegue de los procesos sublimatorios en cada uno y entre los hermanos. En el caso del hermano menor, el recorrido identificatorio genera un trabajo adicional, acrecentándose una bisexualidad que puede llegar a ser sublimada para dar lugar a la creatividad. El hermano menor generalmente es eximido de ser el portavoz y garante responsable de la tradición familiar imperante. Mientras él suele ser el cuestionador y el creador, el primogénito suele ser el conservador.

En relación ahora a los mellizos, Kancyper (2004) argumenta que tal condición tiene una potencialidad traumática, la que determina a su vez conductas particulares entre los hermanos y en la dinámica de los progenitores hacia ellos. La condición de ser mellizo se convertirá efectivamente en trauma en la medida en que el niño y sus padres no la puedan tramitar. Y en cuanto a los gemelos, el autor antes mencionado expone una argumentación original al afirmar que en éstos, al menos en muchos casos, existe la fantasía relacionada con la existencia de un solo espacio, de un solo tiempo y de una sola posibilidad para dos. Es decir que, según esta fantasía, existe por ejemplo una sola carrera profesional, una belleza excluyente, una sola posición económica y social. Y siguiendo esto, podríamos suponer que: si una hermana gemela es madre, la otra sólo será tía; si una es inteligente, la otra es tonta; si una es linda, la otra es fea; si una es rica, la otra es la pobre; etc. Por otra parte, Kancyper agrega que la clínica de las relaciones fraternas, sobre todo de los gemelos, ilustra la dialéctica del Amo y el Esclavo de Hegel, en la cual un hermano es necesariamente dominado por el otro, el dominante. Dice el 
autor que, aquel que domina se preocupa por el otro, tiene mayor necesidad de ese otro

(al que domina) y es a menudo eso lo que le resulta intolerable, y que en cambio el dominado puede prescindir del dominante y se adecua a tal situación.

\section{BIBLIOGRAFÍA}

American Psychological Association. (2001). Publication manual of the American Pshychological Association (5 ${ }^{\text {th }}$ ed.). Washington, DC: Author.

Coscio, R. \& Sánchez, J. (1999). Manual de Psicología. Buenos Aires: Tyché Ediciones.

Freud, S. (1997). Lección XXI - Desarrollo de la libido y organizaciones sexuales. En L. López Ballesteros (Trad.), Obras completas (Vol. 17, pp. 2322-2323). Buenos Aires: Editorial Losada. (Trabajo original publicado en 1916).

Freud, S. (1997). Sobre la psicogénesis de un caso de homosexualidad femenina. En L. López Ballesteros (Trad.), Obras completas (Vol. 12, pp. 2545-2561). Buenos Aires: Editorial Losada. (Trabajo original publicado en 1920).

Freud, S. (1997). Moisés y la religión monoteísta. En L. López Ballesteros (Trad.), Obras completas (Vol. 24, pp. 3241-3326). Buenos Aires: Editorial Losada. (Trabajo original publicado en 1939).

Kancyper, L. (1989). Jorge Luís Borges o el laberinto de Narciso. Buenos Aires: Editorial Paidós.

Kancyper, L. (2004). El complejo fraterno. Buenos Aires: Grupo Editorial Lumen.

Laplanche, J. \& Pontalis, J. (1993). Diccionario de psicoanálisis. Barcelona: Editorial Labor.

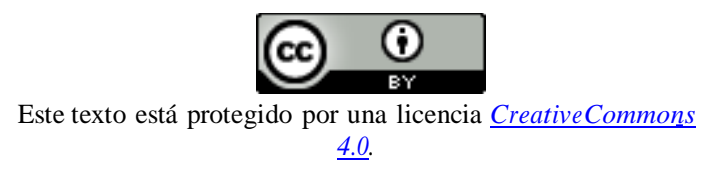

Usted es libre para Compartir — copiar y redistribuir el material en cualquier medio o formato - y Adaptar el documen- to -remezclar, transformar y crear a partir del material- para cualquier propósito, incluso comercialmente, siempre que cumpla la condición de:

Atribución: Usted debe reconocer el crédito de una obra de manera adecuada, proporcionar un enlace a la licencia, e in- dicar si se han realizado cambios. Puede hacerlo en cualquier forma razonable, pero no de forma tal que sugiera que tie- ne el apoyo del licenciante o lo recibe por el uso que hace. 